\title{
APRENDIZAGEM MOTORA PELA FILOSOFIA (S) DA (S) DIFERENÇA (S): POSSIBILIDADES E DESLOCAMENTOS
}

\section{MOTOR LEARNING THROUGH THE PHILOSOPHY OF DIFFERENCE: POSSIBILITIES AND DISLOCATIONS}

Paulo Henrique Oliveira Lopes ${ }^{1}$

Resumo: O presente trabalho busca aproximar a literatura da (s) filosofia (s) da (s) diferença (s) às discussões sobre aprendizagem motora. Tenho como método de pesquisa a proposta de "método como acontecimento" desenvolvida por Ribeiro (2016), na qual a autora considera importante a experiência do pensamento para além dos confrontos epistemológicos e aquém das dimensões ético-políticas. A pesquisa baseia-se em leituras de estudiosos do comportamento motor como: Go Tani e Richard A. Magill; e os filósofos/psicólogos (as) Gilles Deleuze, Henri Bergson, Silvio Gallo e Virginia Kastrup. Relata-se ao final desta pesquisa a possibilidade de pensar a invenção no relacionamento sensório-motor; reivindicando uma dimensão analítica dos afectos neste intermeio.

Palavras-chave: Aprendizagem; motricidade; diferença.

Abstract: This study aims to analyze the discussions on motor learning in the light of the philosophy of difference. The research methodology utilized in this paper draws on the "method as an event" proposal, developed by Ribeiro (2016), in which the author considers the thought experience to be an important ethical-political construction that stretches beyond epistemological arguments. The research is based on readings by scholars of motor behavior such as: Go Tani and Richard A. Magill; and the philosophers / psychologists Gilles Deleuze, Felix Guttari, Henri Bergson, Silvio Gallo and Vírginia Kastrup. The final part of this paper states the possibility of invention in the sensorimotor relationship, claiming an analytical dimension of the affects in the interim.

Keywords: Learning; motricity; difference.

\section{Caminhos muitos - método e pesquisa}

A presente pesquisa tenta aproximar, ciente das complexidades, os estudos de aprendizagem motora aos da filosofia da diferença (s). Para isso, consideramos como via de pesquisa a proposta colocada por Ribeiro (2016) como: método- acontecimento. Para a autora, a escolha consegue abordar uma dinâmica ético-político do problema; desenvolve-se não somente num único âmbito de circulação discursiva, mas também, empenhando-se a propor mudanças levando em conta os dinâmicos e intensivos encontros dos corpos em suas diversas realidades:

Ao evocarmos essa imagem do método como acontecimento, buscamos enfatizar um trabalho analítico de experimentação do pensamento que somente se efetua na imanência. Nesse ato, sequestramos as discussões metodológicas da zona de conforto epistemológico e arremessamos à arenaético político (RIBEIRO, 2016, p. 75).

\footnotetext{
${ }^{1}$ Graduando em bacharelado pela Faculdade de Educação Física da A. C. M Sorocaba, membro do grupo de estudos GEPEF-FEFISO. Sorocaba.E-mail: pauloemail2112@gmail.com.
} 
Aproximados aos pensadores franceses Gilles Deleuze, Félix Guattari e Michel Foucault (e outrxs que trouxeram à tona a discussão sobre a diferença no ambiente acadêmico, literário, científico e filosófico), nos desafiamos a provocar possibilidades as teorias da motricidade aqui consideradas.

Reconhecendo a importância de pesquisadores (as) como: Richard Schimidt, Crain Wrisberg, Richard Magill, David Gallahue, John Ozmun, Jackie Goodway e, especialmente, Go Tani (uma das principais referências de pesquisas em Comportamento Motor no Brasil) na composição deste campo científico. Reconhecemos que tratar de tal assunto sem referenciá-los ou até mesmo rejeitar seus textos e conceitos nos aproximaria de uma prática comum a modernidade.

Este trabalho opera com "convites insuspeitáveis" que são encontrados em nossa jornada (não só por leitura dos artigos presentes na bibliografia como também nos encontros da vida) e, como nos apresenta Gallo (2017): possibilitamos mudanças menores, sem perspectivas emancipatórias. Lançamo-nos a problematizar a literatura da aprendizagem motora com a filosofia(s) da(s) diferença(s). Mas exatamente o que se problematiza nesta pesquisa? De certo o que está parado, ou seja, aquilo que se encontra sob controle.

A seguir, apresentaremos algumas inquietações desenvolvidas durante a pesquisa. Bem como propostas e oportunidades de se pensar a diferença por outro viés e outras conexões.

\section{Aprendizagem motora- inquietações e convites}

Para compressão mínima de aprendizagem motora alguns conceitos serão abordados. Entenderemos inicialmente as dimensões do Comportamento Motor (CM). Para Tani (2008), o CM pode ser explicado como uma área de investigação científico-acadêmica composta por três campos denominados: Desenvolvimento Motor, Aprendizagem Motora e Controle Motor. Essas áreas buscam assim o significado compreender, mecanismo e processo de mudanças referentes ao comportamento motor humano. Os estudos sobre o CM datam de um longo tempo. Pesquisas em Aprendizagem Motora remontam ao final do Séc. XIX provenientes da Psicologia.

Em uma compreensão histórica desta área de pesquisa Fairbrother (2012, p. 18) cita que:

O campo do comportamento motor emergiu em grande parte da psicologia experimental em razão dos esforços para solucionar e treinar eficientemente os pilotos da Segunda Guerra Mundial. Hoje em dia, o comportamento motor se relaciona a uma ampla variedade de campos que também envolvem os estudos do desempenho humano. Estes incluem os fatores humanos, a terapia ocupacional, a educação física, o treinamento, a ciência do exercício e a fisioterapia.

Já segundo Tani (2006), existem três problemas que norteiam os estudos do CM, são eles: os mecanismos responsáveis pela produção do movimento, objeto de estudo do Controle Motor; a compressão dos processos subjacentes resultantes da prática que influenciam no comportamento motor, abordado pelas pesquisas em Aprendizagem Motora; as mudanças motoras ocorrentes no indivíduo ao longo do ciclo da vida, objeto de investigação pelas pesquisas em Desenvolvimento Motor. A partir desta observação, o leitor deve atentar-se que, mesmo que esta pesquisa destaque seu interesse à Aprendizagem Motora, as outras "instituições de pesquisa" podem ser evocadas já que não se pretende entendê-las e sim questionar suas existências.

Ao nos direcionarmos ao Dicionário de Etimologia (1994) vemos que a palavra "aprendizagem" provém do latim: apprehendere, que por sua vez significa "apanhar"; enquanto "motor", advém, também do latim, de: motor-oris, ou seja: o que faz mover. Assim podemos entender de maneira introdutória e simplista, que, qualquer campo do conhecimento que se dedique a comentar sobre a aprendizagem motora, passe a construir sentidos que expliquem como os seres vivos podem apanhar, ou ainda, apreender, o que faz, ou o que produz, o movimento. 
Em Magill (2000, p. 136), o conceito de aprendizagem por ele é definido como: "Uma alteração na capacidade de uma pessoa em desempenhar uma habilidade, que deve ser inferida como uma melhoria relativa permanente no desempenho, devido à prática ou a experiência".

Para o autor, a avaliação dos níveis de aprendizagem ocorre pelo comportamento observável - desempenho. O autor ainda entende desempenho como a efetuação de uma habilidade num determinado momento e em uma determinada tarefa. Sendo assim a aprendizagem não é passível de uma análise direta dependendo sempre das características observáveis desempenhadas pelo indivíduo (MAGILL, 2000).

Já a Aprendizagem Motora é explicada por Schmidt e Wrisberg (2010, p. 213) como "as mudanças, associadas às práticas ou experiências, em processos internos que determinam a capacidade de um indivíduo para executar uma habilidade motora".

Em leitura dos apontamentos anteriores, vemos que a aprendizagem motora se desdobra em razão do tornar-se habilidoso, ou seja, um processo identificado na transformação do comportamento observável, processo esse da consideração de seus estudos como campo do comportamento motor como visto em Fairbrother (2012) e Tani (2006, 2008). Ora, talvez aqui encontremos um convite - como pensar a Aprendizagem Motora fora da ordem "causa" e "efeito" concretizada pelo reconhecimento da mesma como processo temporário que se leva na aquisição de habilidades motoras?

Magill (2000) definirá habilidade como uma forma de resposta a tarefa que por sua vez possui uma finalidade específica a ser atingida. Já as habilidades motoras são vistas pelo autor como habilidades que exigem a movimentação consciente do corpo e/ou de seus membros para atingir objetivos com maior destreza. Devido à existência de diversas habilidades motoras diferentes o autor considera a necessidade da sistematização como forma de encontrar suas semelhanças, sendo assim, as categoriza em: habilidades grossas e finas, de acordo com o número de grupos musculares envolvidos nos movimentos; habilidades discretas e contínuas, pela a existência de pontos iniciais e finais de movimento; habilidades abertas e fechadas, de acordo com a estabilidade do ambiente.

Já quanto à experiência de aprendizagem, Schmidt e Wrisberg (2010, p. 213) a definem como: "situações nas quais as pessoas fazem tentativas deliberadas para aumentar sua performance em um movimento ou ação particular". Os autores destacam ainda que esta experiência pode envolver a um ou mais aprendizes e que nem sempre conta com a orientação de um instrutor, terapeuta ou técnico. Evidenciam quão importantes é ao aqui identificado como "profissional do movimento," estar ciente de que a experiência de aprendizagem pertence ao aprendiz. Afirmam que: "Todo aprendiz aborda uma nova situação de aprendizagem de habilidades com alguma ideia que quer realizar. A experiência de aprendizagem é uma interação entre o instrutor e o aprendiz que deveria focar no alcance de metas do aprendiz (SCHMIDT; WRISBERG, 2010, p. 213).

Seguindo esta linha de raciocínio, esclarecem que a produção de metas de aprendizagem (pelo aprendiz) é um importante requisito para a feracidade deste processo. Assim nos é apresentado uma sequência de metas, sendo elas: metas de resultado, metas de performance, metas de processo, habilidades-alvo, comportamento-alvo e contexto-alvo (SCHMDT; WRISBERG, 2008).

Em uma outra perspectiva Tani (2005) compreende o homem como um "sistema aberto" por estabelecer relações de mudança com o meio ambiente, sendo assim, é importante que este tenha a capacidade de se adaptar a essas mudanças. Descreve ainda que quando um sistema aberto é perturbado existem duas formas de resposta - a) tentar neutralizar a perturbação ou b) fazer da perturbação uma fonte de ordem em direção a estados mais elevados de complexidade. Nesta concepção, a aprendizagem motora ganha a compreensão de “... processo de solução de problemas motores" (BERNSTEIN apud TANI, 2005, p. 65).

Tani (2005) ainda observa que a formação de habilidades motoras possui uma complexidade, aponta que as teorias correntes em aprendizagem motora se debruçam em 
explicar o processo de estabilização da performance, sendo incapazes de produzirem novas estruturas. A automatização do movimento é dado pelo autor como um exemplo de neutralização do processo de aprendizagem. Ainda, acrescenta que estes desencontros produzem paradigmas que, por sua vez, trazem novas questões aos estudos de aprendizagem motora; dessa maneira a concepção do processo de aprendizagem motora como "processo adaptativo" parece primordial para transpassar as situações paradigmáticas, cambiando a atenção de suas pesquisas à desordem e aos inúmeros fatores que afetam a aquisição de habilidades motoras, gerando assim um paradoxo. Como prerrogativa desta mudança, acrescenta novas questões que, segundo ele, guiam as preocupações no Laboratório de Comportamento Motor (LACOM), sendo algumas delas: "como explicar os resultados paradoxais? Como explicar que outro fator relacionado à desordem, qual seja o ruído ou perturbação, facilita a aprendizagem além de prejudicá-la?"” (TANI, 2005, p. 66).

Sobre observações desse novo formato de direcionamento, agora tendo o campo do desenvolvimento motor como plano de aplicação, o pesquisador compreenderá que a adaptação “... ressalta as relações dinâmicas entre indivíduo e ambiente, num processo contínuo em que a definição de início e fim é relativa e geralmente condicionada aos desígnios do observador" (TANI, 2005, p. 72). Esse movimento nos parece primordial já que a mudança proposta por Tani (2005) de fato abre o campo dos estudos do comportamento motor para uma perspectiva além dos paradigmas.

Com essa leitura, nos direcionamos a entender como a aprendizagem é tratada pela filosofia da diferença, mais especificamente aquela desenvolvida pelo filosofo francês Gilles Deleuze e seus "porta-vozes" brasileirxs Silvio Gallo e Virgínia Kastrup, tendo por objetivo pensar conexões e possibilidades para com os estudos da aprendizagem motora.

\section{Filosofia(s) da (s) diferença (s) - deslocamentos}

Como forma a investigar esta situação estagnada produzida na filosofia e ciência moderna, Kastrup (2007) traz deslocamentos a fim de descobrir a cerne destas formulações na psicologia cognitiva. A autora nos apresenta o escrito “Qu'est-ce que les Lumières?" - O que é o iluminismo? (1994) - no qual Foucault comenta uma obra menor Kant (de mesmo título na tradução). Nela Kant teria apresentado uma reflexão distinta as antes formuladas em seus escritos maiores, em que a "filosofia é afetada e levada a pensar por questões do seu próprio tempo" (KASTRUP, 2007, p. 29). Assim, o filósofo francês observa que:

Mas existe na filosofia moderna e contemporânea um outro tipo de questão, um outro modo de interrogação crítica: é esta que se viu nascer justamente na questão da Aufklärung ou no texto sobre a revolução; "O que é nossa atualidade? Qual é o campo atual das experiências possíveis?”. Não se trata de uma analítica da verdade, consistiria em algo que se poderia chamar de analítica do presente, uma ontologia de nós mesmos e, me parece que a escolha filosófica na qual nos encontramos confrontados atualmente é a seguinte: pode-se optar por uma filosofia crítica que se apresenta como uma filosofia analítica da verdade em geral, ou bem se pode optar por um pensamento crítico que toma a forma de uma ontologia de nós mesmos, de uma ontologia da atualidade (FOUCAULT, 1994, p. 8).

Kastrup (em leitura de Foucault) nos apresenta Kant como ponto de inauguração e bifurcação de linhas distintas na filosofia- a analítica da verdade e a ontologia do presente. A primeira anuncia o término da metafísica, valorizando a articulação argumentativa e o seu desenvolvimento inter- 
relacionado. Este movimento é destacado por Comte que cita a ciência como substituta da filosofia. Desta forma, Kastrup (2007) entende a psicologia como analítica da verdade em busca não de prová-la, mas sim, de reconhecer as vias que levam a cognição. Este movimento na psicologia a caracteriza como ciência da cognição já que: sempre está em busca de processos invariáveis tendo como norteamento de sua problemática científica- o que é verdadeiro e o erro; sendo herdeira do positivismo de Comte e a analítica da verdade, buscará na cognição o que ela tem de ordem da necessidade e de repetição. Kastrup (2007, p. 36, p. 40) destaca que:

Nesse caminho, busca determinar as condições do conhecimento verdadeiro que aí se confunde com o emprego de procedimentos e métodos da ciência. A analítica da verdade estuda as representações e suas condições, encontradas no domínio do sujeito, do método ou da linguagem. Para sustentar as representações, essas condições devem ser invariantes, universais e necessárias, à maneira da ciência.

A segunda é denominada por Foucault como ontologia do presente, na qual se encontramos como problema central: o tempo - seja como investigação histórica (Marx, Hegel e a Escola de Frankfurt) ou como imprevisibilidade. (Nietzsche, Bergson). Conectando às palavras de Foucault, Kastrup aprofunda-se trazendo os pensamentos do filosofo Henry Bergson, apresentando-o como filósofo do devir, não como uma característica que o identifica, mas como quem que conduzia suas teses contemporâneas às descobertas científicas tomando como base um o tempo extemporâneo. Kastrup (2007) nos apresenta o pensamento bergsoniano como restaurador da aproximação entre ciência e a filosofia a fim de que a primeira ultrapasse seus limites e sua dependência dos quadros referência traçados pela inteligência. A autora aponta que: “... a ontologia do presente constitui-se como crítica de todas as categorias invariantes" (KASTRUP, 2007, p. 40), e em seguida:

Procurando explicar o que seria o ultrapassamento dos limites da ciência, indica que o principal limite é transpor o cientificismo ou intelectualismo. Este se revela no encaminhamento do trabalho científico a partir de problemas já colocados, como se estes, formulados pela linguagem e traduzidos em conceitos de inteligência, correspondem ao real. (KASTRUP, 2007 p. 42)

Bergson problematiza a linguagem intelectiva, nos apresentando um método que esteja atento à fluidez da própria vida, sendo a intuição o que possibilita o acesso ao que é real. Nesta ideia, o tempo está tomado pela sua duração e não com espaço percorrido. "Assim, se observa que a teoria bergsoniana consiste em eregir um novo método pera a filosofia, isto é, uma nova metafísica capaz de abordar questões mais significativas decorrentes da existência: a vitalidade e seu brotar, sua fluidez, o movimento impregnado ao ser. (VILHENA, 2017, p. 191).

E seguida, outros fenômenos da modernidade nos é apresentado pela autora, agora com Latour. O primeiro deslocamento nos diz respeito à o que Latour conceitua como práticas de purificação, onde se privilegia separações por identificação do sujeito e de um objeto “... homens e coisas, agora reunidos sobre os signos de representação, pois podem ser purificados e circunscritos em suas identidades" (KASTRUP, 2007, p. 46).

A segunda é colocada como "hibridização", esta ocorre em aversão à modernidade, sendo "seres que furtam à representação, que resistem a redução das formas puras" (KASTRUP, 2007, p. 46). Desta forma, vivem em uma constante guerra dentro a modernidade e seus híbridos que, por sua vez, fogem de suas categorizações criando assim o chamado aqui por Latour como "paradoxo da modernidade" (KASTRUP, 2007). 
O paradoxo moderno consiste na sua criação relativista, onde ora se intenta a pensar os híbridos ora se guia a evitá-los e reduzi-los a fato um regime das representações. Sobre esta questão Deleuze (1983) pontua que a revolução da "relatividade", apesar da tentativa de inverter a ordem de análise, que não dependem mais de instantes privilegiados (poses) mas sim de instantes quaisquer (cortes da realidade) podendo assim interpretar o tempo como uma "variável independente", retornando o tempo a um instante qualquer para que possa ser analisado. Ainda sobre tal inversão, cita que:

Qual o interesse de um tal sistema? Do ponto de vista da ciência, muito superficial. Pois a revolução científica era de análise. E se era necessário reportar o movimento ao instante qualquer para poder analisá-lo, não se percebia o interesse de uma síntese ou de uma reconstituição fundada no mesmo princípio, a não ser um vago interesse de confirmação (DELEUZE, 1983, p. 11).

Aproximados aos deslocamentos de Kastrup, observamos os preceitos da psicologia comportamental que se utiliza da análise experimental do comportamento, ou seja, o que se é observável. A mesma encontra-se em busca da "identificação das contingências" e funcionalidades na relação homem-ambiente, por isso, observamos que esta psicologia, assim como a psicologia da cognição, abraça-se na analítica da verdade já que procura nestas relações humanas a criação de teorias funcionais- úteis- a fim de tornar perceptíveis os acontecimentos (TODOROV, 2007). Desta forma o que será reconhecido como conhecimento científico é o que funciona.

Como visto, a psicologia experimental exerce influência sobre o desenrolar acadêmico do Comportamento Motor que, por sua vez, herda as concepções analíticas desta ciência especialmente quanto a aspectos do desempenho, percepção e aprendizado (FAIRBROTHER, 2012). Entretanto, o objeto de estudos do Comportamento Motor é regido pela busca da clarificação do movimento humano. Fairbrother (2012) cita ainda que as disciplinas subjacentes condizem com esse objeto de estudo e que as três (controle motor, desenvolvimento motor e aprendizagem motora) interessam-se pela especialidade dos movimentos e clarificação dos aqui chamados de distúrbios do movimento.

Como "filha" de ciência analítica, a ciência da aprendizagem motora explora em suas próprias concepções- ou melhor, nas concepções científicas dos estudos do comportamento motor humano - a fim de operar na realidade, entretanto, como já observado por nós e pelos próprios estudiosos do comportamento motor, essas estruturas não dão conta de explica-la. Como vemos em Gallahue, Ozmum e Goodway (2013, p. 22) neste trecho que condensam os objetivos das pesquisas em desenvolvimento motor: "O desenvolvimento motor é um processo contínuo que começa na concepção e cessa com a morte. Ele envolve todos os aspectos do comportamento motor humano, em consequência, só pode ser separado em "domínios", "estágios" e "faixas etárias" de forma artificial".

Assim como Kastrup, que encontra na psicologia cognitiva formas invariáveis de interpretação dos processos cognitivos que por sua vez descartam o tempo como duração tomando-o como espaço, formulando leis invariantes, rejeitando as possibilidades e a invenção do ser, em prol da inteligibilidade e cientificismo - encontramos nos estudos da aprendizagem motora sua concepção como processo do inabilidoso ao habilidoso, generalizando sua ocorrência. Entretanto, estas formulações são abaladas ou, como Tani (2005) verifica: desequilíbrios que, de forma insistente, instigam a formação de outras estruturas.

Como proposta de intensificar nosso problema, tomaremos para as próximas seção o conceito de afecto tal qual desenvolvida pelo filosofo francês Henri Bergson, tencionando ainda mais a questão do tempo, aprendizagem e movimento corporal. 


\title{
Os afectos - corpo e pensamento na produção do movimento
}

\author{
Tudo se passa como se, nesse conjunto de imagens \\ que chamo de universo, nada se pudesse produzir de \\ realmente novo a não ser por intermédio de certas \\ imagens particulares cujo modelo me é fornecido por \\ meu corpo \\ Bergson (1999, p. 12).
}

No primeiro capitulo de Matéria e Memória, Bergson descreve a importância do corpo na construção da novidade. Para o autor, dentre as diversas imagens que agem e reagem sobre si numa constante da natureza, uma tende a se prevalecer sob as demais. Essa imagem prevalecida é oriunda do corpo. Não somente da percepção, ou seja, na medida que conheço as formas das coisas, como também na medida que mesclo sua composição com o de dentro "mediante as afecções: o corpo" (BERGSON, 1999, p. 11).

Para Marques (2006), está é a manifestação da singularidade de um corpo; melhor dizendo: a afecção produz um "delay" entre a sensação e a ação propriamente motora, interrompendo a mecaneicidade e as relações de necessidade, entende que "[...] são os movimentos imprevisíveis do corpo, em relação aos previsíveis e necessários da natureza, o que lhe confere singularidade" (p. 52). A imprevisibilidade com aquilo que o corpo se afecta inviabiliza sua representação; pontua-se, por via dessa relação, o corpo como "aparelho" de liberdade (MARQUES, 2006).

A palavra "afecção" deriva da palavra latina affecio, refere-se ao "[...] plano de factilidade, ou seja, o que me chega, o que se impõe a mim, aquilo que me faz, me constitui " (ROCHA; KASTRUP, 2009, p. 387). Este vinculo, por sua vez, não se refere a uma particularidade interior ou exterior, mas sim, ao meio - no sentido de inexistência de pertencimento, mas sim, acontecimentos.

Para Rocha e Katrup (2009), está capacidade de ser afctado tembém gera um força afetiva, manifesta por dois sentidos: “(1) Há um movimento corporeificado que se manifesta como possuído por uma força afetiva (affect-felling force)." e " Tal movimento é inseparado de sua manifestação visível: postura, posição, mudanças na face, na respiração, batimento cardíaco, sensações de arrepio, etc; e apresenta componentes invisíveis como mudanças difusas: o tom da voz, a inflexão do olhar, um certo direcionamento do movimento, etc" (idem, p. 390). As autoras consideram essas manifestações visíveis e invisíveis como manifestações intensivas do afecto; nos alertando, ao contrário do que se possa pensar, de que estas não representem um sentido próprio de tendência, mas sim, de um interesse (VARELA;DEPRAZ, 2000 apud ROCHA; KASTRUP, 2009).

$\mathrm{O}$ espectro alcançado pelos autores desviam do espectro movimentado em algumas teorias mais recentes da aprendizagem motora. Tani, Buzi, Bastos e Chiviacowsky (2011), descrevem a aprendizagem motora tendo como base a perspectiva cognitivo-social, elencando perspectivas e propostas para uma mudança de paradigma. O movimento que optei para este trabalho, por sua vez, têm proposto uma dimensão inventiva da cognição; abarcando a dimensão motriz da motricidade.

A palavra motricidade caracteriza-se como uma particularidade do que é motriz (força que impulsiona) (DICIONÁRIO ONLINE, 2020). Diante dessa perspectiva, pensar aprendizagem motora na dimensão inventiva é pensar as forças impulsivas que reivindicam um meio da ralação sensório-motora, relações motrizes que tomam o corpo na experiência com o presente. Aprendizagem motriz - dimensão afetiva que germina possibilidades de agir e não agir, é quantitativo e qualitativo ao mesmo tempo - intempestividade de si. "À medida que o inventor realiza detalhes de sua máquina, ele renuncia a uma parte do que queria dela obter ou obtém outra coisa" (BERGSON, 2006, p. 137). 
A experiência de aprendizagem consiste então, antes de uma ação propriamente dita, uma problematização. "Não se trata de mera ignorância, mas de estranhamento e tensão entre o saber anterior e a experiência presente", "Quando viajamos somos forçados a conviver com uma certa errância, a perder tempo, a explorar o meio com olhos atentos aos signos e a penetrar em semióticas novas", alerta-nos Kastrup (2001, p. 17) que converge a um "exercício" que Deleuze traz à tona me Diferença e Repetição: é preciso dar alma aos músculos.

\section{Considerações finais}

Questionar a motricidade e ainda dar sentido aos movimentos corporais gera um grande empenho e diversas teorias no curso de Educação Física. Dentre estas teorias, escolhi adentrar pela ciência da Aprendizagem Motora. Em sua história de composição, fora influenciada por diversas outras ciências, como: o comportamentalismo e a psicologia experimental, estudos da cognição etc. O que identifiquei neste processo e que sustentou minha problematização é desamparo próprio; neste desamparo, vi como proposta pensar a dimensão inventiva da cognição.

Os "resultados" deste trabalho me encorajam a seguir pesquisando sobre as relações sensório-motoras que, como defendi, são acometidas de sentidos tanto quantitativos quanto qualitativos. Muitas outras perguntas me surgiram, das quais posso citar: quais são os discursos sustentam o sentido de motricidade? Quais são os pensamentos atuais em relação ao movimento corporal? Mas também, muitas coisas ficaram evidentes neste processo, dentre elas a de que: o processo de aprendizagem pode estar além do reconhecimento de formas externas ou representação interior do mundo; a motricidade não é uma capacidade desassociada da cognição, ou ainda, do pensamento - toda aprendizagem é motora; o afecto corresponde a maneira singular pela qual somos atingidos pelo fora, implica em uma experimentação de distanciamento do habitual, assim como um experimentação das possibilidades do Outro; os movimentos corporais são a maneira pela qual os corpos interagem com mundo; pensar a aprendizagem motora como parte do processo inventivo da cognição é tirar os pés das certezas, criar novas formas de agir e resistir àquelas que travam a "vida". Como pensei em algum momento dizer: pensar a dimensão motriz da aprendizagem.

\section{Referências}

BERGSON, Henri. Matéria e memória: ensaio sobre a relação do corpo com o espírito. São Paulo, SP: Martins Fontes, 1999, 291 p.

BERGSON, Henri. O esforço intelectual. Trans/Form/Ação, Marília, v. 29, n. 1, p. 123-146, 2006. Disponível em: $\quad$ http://www.scielo.br/scielo.php?script=sci_arttext\&pid=S010131732006000100008\&lng=en\&nrm=iso. Acesso em: 05 nov. 2019. http://dx.doi.org/10.1590/S0101$\underline{31732006000100008 .}$.

DELEUZE, GILLE. Cinema: a imagem-movimento. Editora Brasiliense, 1983, 244 p.

DICIONÁRIO ONLINE de Português. Porto: 7Graus, 2020. Disponível em: https://www.dicio.com.br/motricidade/. Acesso em: 10/07/2020.

FAIRBROTHER, Jeffrey. Fundamentos do comportamento motor. Barueri, SP: Manole, 2012. 167p. 
FOUCAULT, Michel. O que é o iluminismo? Dits et écrits, vol. 4. Paris: Gallimard, 1994, p. 679-688.

GALLAHUE, David L.; OZMUN, John C.; GOODWAY, Jacqueline D. Compreendendo o desenvolvimento motor: bebês, crianças, adolescentes e adultos. Porto Alegre, RS: AMGH. 2013, 487 p.

GALlO, Silvio. Deleuze \& educação. Belo Horizonte, MG: Autêntica Editora: 2017, 104 p.

KASTRUP, Virgínia. Aprendizagem, arte e invenção. Psicologia em Estudo, Maringá, PR, n. 1, p. 17-27, jan./jun. 2001.

KASTRUP, Virgínia. A invenção de si e do mundo: uma introdução do tempo e do coletivo no estudo da cognição. Belo Horizonte, MG: Autêntica, 2007. 256 p.

MARQUES, Silene T. Ser, tempo e liberdade: as dimensões da ação livre na filosofia de Henri Bergson. São Paulo, SP: Associação Editorial Humanitas, 2006. 157 p.

MAGILL, Richard A.; ERICK G. H. Aprendizagem motora: conceitos e aplicações. São Paulo, SP: Edgard Blucher, 2000. 384 p.

RIBEIRO, Cintya R. O agenciamento Deleuze-Guattari: Considerações sobre o método de pesquisa e formação em educação. Educação Unisinos, São Leopoldo, RS, v. 20, p. 68-75, 2016.

ROCHA, Jerusa Machado; KASTRUP, Virgínia. Cognição e emoção na dinâmica da dobra afetiva. Psicol. estud. [online], v. 14, n. 2, p. 385-394, 2009. Disponível em: http://www.scielo.br/scielo.php?script=sci_arttext\&pid=S1413-

73722009000200020\&lng=en\&nrm=iso. Acesso em: 05 fev. 2020. ISSN 1413-7372. http://dx.doi.org/10.1590/S1413-73722009000200020.

SCHMDT, Richard A.; WRISBERG, Craig. A. Aprendizagem e performance motora. 4. ed. Porto Alegre, RS: Artmed, 2010, 416 p.

TANI, Go. Comportamento motor: aprendizagem e desenvolvimento. Rio de Janeiro, RJ: Guanabara Koogan, 2005. 333 p.

TANI, Go. Comportamento motor e sua relação com a educação física. Brazilian Journal of Motor Behavior, São Paulo, SP, n. 1, p. 20-31, 2006.

TANI, Go. Abordagem desenvolvimentista: 20 anos depois. Journal of Physical Education, Maringá, PR, n. 3, p. 313-331, 3 trim. 2008.

TANI, Go; BRUZI, Alessandro Teodoro; BASTOS, Flavio Henrique; CHIVIACOWSKY, Suzete. O estudo da demonstração em aprendizagem motora: estado da arte, desafios e perspectivas. Rev. bras. cineantropom. desempenho hum. [online], v. 13, n. 5, p. 392-403, 2011. Disponível em: http://www.scielo.br/scielo.php?script=sci_arttext\&pid=S1980-

00372011000500011\&lng=en\&nrm=iso. Acesso em: 02 fev. 2020. ISSN 1980-0037. https://doi.org/10.5007/1980-0037.2011v13n5p392. 
TODOROV, João C. A psicologia como estudo de interações. Psicologia: Teoria e Pesquisa, Brasília, DF, n. especial, p. 57-61, 2007.

VILHELA; Adilson L. Intuição e inteligência: crítica bergsoniana à linguagem metafísica tradicional. PERI-Revista de Filosofia, Florianópolis, SC, n. 02, p. 184-196, 2017. 